Myelodysplastische Syndrome

\section{Einfluss der Eisenchelationstherapie auf das Überleben}

\begin{abstract}
Effektive, risikoadaptierte Therapiestrategien haben die Prognose für Patienten mit Myelodysplastischem Syndrom (MDS) in den letzten Jahren deutlich verbessert. Entscheidend ist in über $90 \%$ der Fälle eine gute supportive Therapie, bei der die Substitution von Erythrozytenkonzentraten im Vordergrund steht.
\end{abstract}

Eine hohe Transfusionslast, die mit steigenden Serum-Ferritinwerten einhergeht, bedeutet für MDS-Patienten einen negativen prognostischen Faktor für die allogene Stammzelltransplantation. Experten wie Wolf-Karsten Hofmann, Mannheim, fordern deshalb eine konsequente Eisenchelat-Therapie für Patienten mit myelodysplastischem Syndrom und Eisenüberladung, um die Lebenserwartung zu verlängern.

Internationale Leitlinien empfehlen eine Eisenchelat-Therapie bei MDS-Patienten, deren Serum-Ferrintinspiegel $>1.000 \mathrm{ng} /$ $\mathrm{ml}$ ist, die über einen Zeitraum von mindestens einem Jahr mehr als zwei Erythrozytenkonzentrate monatlich erhalten, die auf eine primäre Therapie nicht ansprechen oder für eine Stammzelltransplantation vorgesehen sind, sowie bei MDS-Patienten mit beeinträchtigter Organfunktion [Bennett JM et al. Am J Hematol 2008;83(11):858-61].

Aktuelle Daten aus einer prospektiven, nicht randomisierten Studie zeigen, dass MDS-Patienten, die nach IPPS (International Prognostic Scoring System) der Risikogruppe „low“ oder „inter- mediate-1“ angehören, unter regelmäßiger Anwendung von Eisenchelatoren einen signifikanten Überlebensvorteil haben (115 vs. 51 Monate ohne EisenchelatTherapie) [Rose C et al. Leuk Res 2010;34(7):864-70].

Außerdem ergab die EPIC (Evaluation of Patients' Iron Chelation with Exjade ${ }^{\circledast}$ )-Studie eine Verbesserung der Leberfunktion: Die Serumwerte der Alanin-Aminotransferase (ALT) verringerten sich signifikant unter der oralen Therapie mit dem Eisenchelator Deferasirox [Gattermann N et al. Leuk Res. 2010;34:1143-50].

Häufigste Nebenwirkungen dieser Therapie sind Durchfälle, ein bis vier Stunden nach Einnahme, die bei den meisten $\mathrm{Pa}$ tienten jedoch nur in den ersten vier bis sechs Wochen auftreten.

ufo

Quelle: Satelliten-Symposium im Rahmen der DÖSGHO-Jahrestagung am 3. Oktober 2010 in Berlin; Veranstalter: Novartis Oncology

\section{Kurz notiert}

Docetaxel-Generikum eingeführt

Seit Ende 2010 bietet die Firma medac in Deutschland das generische Docetaxel (Taxceus ${ }^{\circledR}$ ) an. Der MitoseInhibitor ist als Konzentrat in einer Durchstechflasche (Ein-Vial-System) zum Herstellen einer Infusionslösung erhältlich. Er liegt in den Wirkstärken 20, 80 und 140 mg vor (als N1-Packung mit einer Durchstechflasche). Das Konzentrat wird der Infusionslösung (0,9\%ige NaCl-Lösung oder 5\%ige Glukose-Lösung) direkt zugegeben. Der Patient bekommt es als intravenöse Infusion über eine Stunde unter normalen Lichtverhältnissen. Somit entfällt der anfängliche Verdünnungsschritt, der beim 2-Vial-System (je eine Durchstechflasche mit Konzentrat und eine mit Verdünnungsmittel) notwendig ist. Wie beim Original umfassen die Indikationen für die Anwendung Brustkrebs, nicht-kleinzelliges Bronchialkarzinom, Prostatakarzinom, Adenokarzinom des Magens und KopfHals-Karzinome. Weitere Informationen sind unter der Tel.Nr. 04103-8006-405 erhältlich. medac

\section{Ovarialkarzinom}

\section{Bevacizumab verlängert progressions- freies Überleben}

\section{Zusätzliches Bevacizumab zur Standard-Chemotherapie mit an- schließender Bevacizumab-Erhaltungstherapie verlängert das pro- gressionsfreie Überleben von Patientinnen mit Ovarialkarzinom.}

Dies zeigten die Ergebnisse der randomisierten Phase-III-Studie ICON7, die Tim Perren, Leeds/ Großbritannien auf dem letztjährigen ESMO-Kongress in Mailand vorstellte [Porren T et al. ESMO 2010; Abstract LBA4].

An der multizentrischen unverblindeten Studie nahmen 1.528 Frauen mit unbehandeltem epithelialem Ovarialkarzinom, primärem Peritonealkarzinom oder primärem Eileiterkarzinom teil. Die Patientinnen im ersten Studien-Arm erhielten die Standard-
Chemotherapie aus Paclitaxel und Carboplatin. Im zweiten Arm bekamen die Patientinnen Bevacizu$\mathrm{mab}(7,5 \mathrm{mg} / \mathrm{kg})$ in Kombination mit der Standard-Chemotherapie, gefolgt von Bevacizumab allein über einen Zeitraum von bis zu zwölf Monaten. Das progressionsfreie Überleben lag im Bevacizumab-Arm median bei 18,3 Monaten (vs. 16 Monate im Standard-Chemotherapie-Arm, Hazard Ratio $=0,79 ; \mathrm{p}=0,001$ ).

\section{Roche Pharma}

